\title{
ERRATUM
}

\section{Can written information material help to increase treatment motivation in patients with erectile dysfunction? A survey of 1188 men}

\author{
C Günzler, L Kriston, V Stodden, C Leiber and MM Berner
}

International Journal of Impotence Research (2007) 19, 531; doi:10.1038/sj.ijir.3901601

Correction to: International Journal of Impotence Research (2007) 19, 330-335. doi:10.1038/sj.ijir. 3901531

Following the publication of this article, it was discovered that the second author of reference 26 was not cited. The missing co-author's name is
Carmita Abdo and the correct reference should read as follows:

26. Melnik T, Abdo CH. Psychogenic erectile dysfunction: comparative study of three therapeutic approaches. J Sex Marital Ther 2005; 31: 243-255. 